\title{
Personal Relationship in Les Murray’s Poem
}

\author{
Henriono Nugroho \\ English Department, Faculty of Letters, Jember University, \\ Kalimantan 37, Jember 68121 East Java, Indonesia \\ e-mail:h-nugroho@hotmail.com
}

\begin{abstract}
Stylistics is a linguistic analysis on literary and non-literary texts. This article is concerned with a systemic stylistic analysis on a poem in terms of Systemic Functional Linguistics and Verbal Art Semiotics. It uses library research, qualitative data, documentary study, descriptive method and intrinsic-objective approach. The semantic analysis results in both automatized and foregrounded meanings. Then the automatized meaning produces lexical cohesion and in turn, it produces subject matter. Meanwhile, the foregrounded meaning produces the literary meaning and in turn, it creates theme. Finally, the analysis indicates that the subject matter is about daily works, the literary meaning is about the complete severance and the theme is about personal relationship.
\end{abstract}

Key words: automatized meaning, foregrounded meaning, subject matter, literary meaning, theme

Generally, there are several theories of stylistics namely formal, functional, feminine, pragmatic, affective, cognitive, pedagogical and critical (Webber, 1996). Particularly the functional stylistics includes Functionalism, Systemic Functionalism, Tagmemics, Prague School Functionalism and West Coast Functionalism (Matthiessen, 1995). Based on Systemic Functional Linguistics, language can be ordered in contexts with cline of instantiation (actualization over time): context of culture and language, situation types and registers, situations and texts, and situation and text (Halliday \& Matthiessen, 1999). According to Halliday and Matthiessen (1999), moreover, context of culture (cultural context) concerns meaning potential (overall meaning), and context of situation (situational context) deals with the actualization of meaning potential (actualized meaning potential). Meanwhile, Kluckhohn (1953) claims that culture (cultural context) refers to notions, values and norms, whereas the domain of socio-cultural context corresponds to universal categories such as language, art, science, technology, economy, social organization and religion. The language order is outlined in Figure 1. 


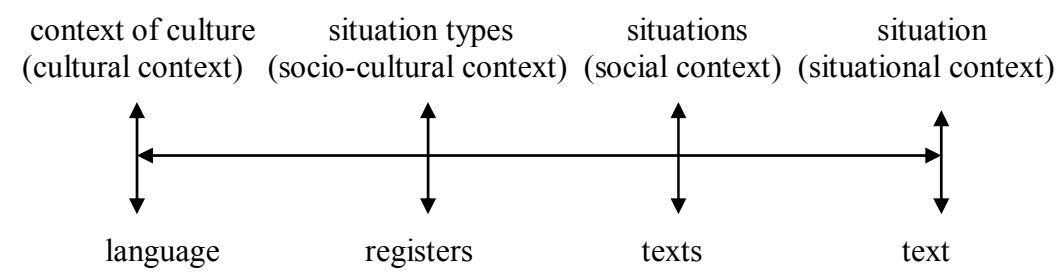

Figure 1. The Interrelatedness of Context, Language, Situation and Text

Note: $\quad$ stratification $=\downarrow \quad$ and instantiation $=\longleftrightarrow$

In fact, a text is a semantic unit and a clause is a grammatical unit (Halliday, 1994). Then, semantics is an interface between context of situation and lexicogrammar; in this sense the semantic systems are related "upward" to contextual systems and they are related "downward" to lexicogrammatical systems (Halliday, 1993). The contextual systems are Field, Tenor and Mode. The semantic systems are Ideational, Interpersonal and Textual Meanings. The lexicogrammatical systems are Complexing, Transitivity, Mood and Theme. In addition, the semantic systems are related "sideways" to discoursal systems (Eggins, 1994). The discoursal systems are structural conjunction, lexical cohesion, conversational structure and grammatical cohesion. The interrelationship of situation, discourse, semantics and lexicogrammar is diagrammed in Table 1.

Moreover, literariness is defined as the difference between automatization or background and defamiliarization or foreground (Jefferson, 1995, p. 37). Background is also called ground, automatization, familiarization, and the normal, habitual, canonical, common, automatized or familiarizing pattern, whereas foreground(ing) is also called figure, deautomatization, defamiliarization, and the foregrounded, motivated, prominent, dominant, deautomatized or defamiliarizing pattern (Jefferson 1995, Hasan 1985, Halliday 1971). Then, the concept of background and foreground is used by Hasan $(1985$, p. 99$)$ to propose the semiotic system of verbal art. The verbal art semiotics deals with verbalization, symbolic articulation and theme, and verbalization itself is the semiotic system of language concerned with phonology, lexicogrammar and semantics. Especially, verbalization - the lowest stratum - is where the point of primary contact with work reveals the meaning of language (the deep level 
of meaning). Symbolic articulation - the middle stratum - is where the deep level of meaning functions as a sign, symbol or metaphor for the deeper level of meaning. Finally, theme - the highest stratum - is where the deeper level of meaning creates the deepest level of meaning.

Table 1. The Relation of Context, Text and Clause

\begin{tabular}{|c|c|c|c|c|c|}
\hline 苞 & Situation & $\begin{array}{r}\text { Fic } \\
\text { Subject }\end{array}$ & $\begin{array}{l}\text { eld } \\
\text { Matter }\end{array}$ & $\begin{array}{c}\text { Tenor } \\
\text { Role Relation }\end{array}$ & $\begin{array}{c}\text { Mode } \\
\text { Rhetoric }\end{array}$ \\
\hline \multirow{2}{*}{ 島 } & Discourse & $\begin{array}{c}\text { Structural } \\
\text { Conjunction }\end{array}$ & $\begin{array}{c}* * \text { Lexical } \\
\text { Cohesion }\end{array}$ & $\begin{array}{c}\text { Conversational } \\
\text { Structure }\end{array}$ & $\begin{array}{c}\text { * Grammatical } \\
\text { Cohesion }\end{array}$ \\
\hline & Semantics & $\begin{array}{l}\text { \# Logical } \\
\text { Meaning }\end{array}$ & $\begin{array}{c}\# \\
\text { Experiential } \\
\text { Meaning }\end{array}$ & $\begin{array}{c}\text { Interpersonal } \\
\text { Meaning }\end{array}$ & $\begin{array}{l}\text { Textual } \\
\text { Meaning }\end{array}$ \\
\hline 苞 & Lexicogramm & Complexing & Transitivity & *** Mood & Theme \\
\hline
\end{tabular}

Note: \# Logical Meaning \& Experiential Meaning = Ideational Meaning

* Including Reference, Substitution, Ellipsis and Cohesive Conjunction

** Including Reiteration \& Collocation

*** Including Polarity and Modality

This article is concerned with a systemic stylistic analysis on a poem of Les Murray shown as follows

\section{Widower in the Country}

I'll get up soon, and leave my bed unmade I'll go outside, and split off kindling wood From the yellow box log that lies beside the gate And the sun will be high, for I get up late now. I'll drive my axe in the log, and come back in With my armful of wood, and pause to look across The Christmas paddocks aching in the heat, The windless trees, nettles in the yard, 
And then I'll go in, boil water and make tea. This afternoon, I'll stand out on the hill And watch my house away below and that The roof reflects the sun and makes my eyes Water and close on bright webbed visions smeared On the dark of my thoughts to dance and fade away Then the sun will move on, and I'll simply watch Or work, or sleep and evening will draw in Before the dark, I'll also go home, light the lamp And eat my corned beef supper, setting there At the head of the table, then I'll go to bed. Last night I thought I dreamed but when I woke The screaming was a possum skiing down the iron Roof on little moonlit claws

(Les Murray)

\section{SEMIOTIC SYSTEM OF LANGUAGE}

A semiotic system of language deals with Logical Semantics, Experiential Semantics, Interpersonal Semantics, Textual Semantics, Logogenetic Process, Lexical Cohesion and Subject Matter.

\section{Logical Semantics, Logical Meaning or Logical Metafunction}

Logical Semantics functions as a resource for constructing logical relation (Halliday, 1994, p. 36). Moreover, Halliday (1994) states that logico-semantic relation deals with taxis (parataxis and hypotaxis), expansion (elaboration, extension and enhancement) and projection (locution and idea). Parataxis is the linking of elements of equal status; both the initiating and the continuing elements are free, in the sense that each could stand as a functioning whole. Paratactic structures are represented by the Arabic numerical notation: 1, 2, 3, and so on. Hypotaxis is the binding of elements of unequal status, the dominant element is free, but the dependent element is not. Hypotactic structures are represented by the Greek alphabetical notation: $\alpha, \beta, \gamma$, and so on. Elaboration (i.e.) means that one clause expands another by elaborating on it (or some portion of it): restating in other words, specifying in greater detail, commenting, or exemplifying. Extension (and, or) means that one clause expands another 
by extending beyond it: adding some new element, giving an exception to it, or offering an alternative. Enhancement (so, yet, then) means that one clause expands another by embellishing around it: qualifying it with some circumstantial feature of time, place, cause and condition. Locution (says) means that one clause is projected through another, which presents it as a locution, a construction of wording. Idea (thinks) means that a clause is projected through another, which represents it as an idea, a construction of a meaning. For example, paratactic elaboration $\rightarrow$ John didn't wait: he ran away $(1=2)$. Hypotactic elaboration $\rightarrow$ John ran away, which surprised everyone $(\alpha=\beta)$. Paratactic extension $\rightarrow$ John ran away, and Fred stayed behind $\left(1^{+} 2\right)$. Hypotactic extension $\rightarrow$ John ran away, whereas Frank stayed behind $\left(\alpha^{+} \beta\right)$. Paratactic enhancement $\rightarrow$ John was scared, so he ran away $\left(1^{x_{2}}\right)$. Hypotactic enhancement: John ran away, because he was scared $\left(\alpha^{\mathrm{x}} \beta\right)$. Paratactic locution $\rightarrow$ John said, "I'm running away" (1 "2). Hypotactic locution: John said that he was running away $(\alpha$ " $\beta)$. Paratactic idea $\rightarrow$ John thought, "I'll run away" (1 '2). Hypotactic idea: John thought that he would run away $(\alpha$ ' $\beta$ ).

Then, logical meaning describes a clause type (clause complex). In fact, the poem is realized by 7 clause complexes consisting of 7 main clauses and 32 expanding clauses. Out of 32 expanding clauses, there are 17 clauses of paratactic extension, 5 clauses of hypotactic elaboration, 4 clauses of hypotactic enhancement, 4 clauses of hypotactic projection, and 2 clauses of paratactic enhancement. Thus, extension is the automatized pattern or the background of the poem, because the poem is normally realized by paratactic extending clauses. The logical semantics is realized by complexing and the complexing analysis is shown in Table 2 .

\section{Table 2. The Analysis of Complexing}

\begin{tabular}{ccll}
\hline No. & Notation & Logical Relation & Clause \\
\hline 1. & 1 & Main clause & I'll get up soon \\
2. & +2 & Extension & And I'll leave my bed unmade \\
3. & 1 & Main Clause & I'll go outside \\
4. & ${ }^{+} 2 \alpha$ & Extension & I'll split off kindling wood \\
5. & $2=\beta$ & Elaboration & That lies beside the gate \\
6. & +3 & Extension & And the sun will be high \\
7. & $x_{4}$ & Enhancement & For I get up late now \\
8. & 1 & Main Clause & I'll drive my axe in the log \\
\hline
\end{tabular}




\begin{tabular}{|c|c|c|c|}
\hline 9. & ${ }^{+} 2$ & Extension & And I'll come back with... \\
\hline 10. & $=3 \alpha$ & Extension & And I'll pause \\
\hline 11. & $3{ }^{\mathrm{x}} \beta$ & Enhancement & To look across Christmas paddocks \\
\hline 12. & $3 \beta=\beta$ & Elaboration & Aching in the heat \\
\hline 13. & ${ }^{+} 4$ & Extension & And then I'll go in \\
\hline 14. & +5 & Extension & [ I'll ] boil water \\
\hline 15. & ${ }^{+} 6$ & Extension & And [ I'll ] make tea \\
\hline 16. & 1 & Main clause & This afternoon I'll stand out ... \\
\hline 17. & ${ }^{+} 2$ & Extension & And I'll watch my house \\
\hline 18. & ${ }^{+} 3 \alpha$ & Extension & And I'll watch \\
\hline 19. & $3 ’ \beta 1$ & Projection & How the roof reflects the sun \\
\hline 20. & $3 ' \beta 2$ & Projection & And the roof makes any eyes water \\
\hline 21. & $3 ’ \beta 3$ & Projection & And the roof makes my eyes close \\
\hline 22. & $3 \beta 3=\beta 1$ & Elaboration & Smeared in the dark of my thoughts \\
\hline 23. & $3 \beta 3^{x} \beta 2$ & Elaboration & To dance \\
\hline 24. & $3 \beta 3^{x} \beta 3$ & Elaboration & And to fade away \\
\hline 25. & 1 & Main clause & Then the sun will move on \\
\hline 26. & ${ }^{+} 2$ & Extension & And I'll simply watch \\
\hline 27. & ${ }^{+} 3$ & Extension & Or I'll work \\
\hline 28. & ${ }^{+} 4$ & Extension & Or I'll sleep \\
\hline 29. & ${ }^{+} 5$ & Extension & And evening will draw in \\
\hline 30. & 1 & Main clause & Before the dark, I'll go home \\
\hline 31. & ${ }^{+} 2$ & Extension & [I'll] light the lamp \\
\hline 32. & ${ }^{+} 3 \alpha$ & Extension & [I'll] eat corned beef supper \\
\hline 33. & $3=\beta$ & Elaboration & Setting there at the head ... \\
\hline 34. & $x_{4}$ & Enhancement & And then I'll go to bed \\
\hline 35. & $1 \alpha$ & Main clause & Last night I thought \\
\hline 36. & $1 ’ \beta$ & Projection & [that] I dreamed \\
\hline 37. & ${ }^{+} 2 \alpha \alpha$ & Extension & $\begin{array}{l}\text { But }<<39>>\text { the screaming was a } \\
\text { possum }\end{array}$ \\
\hline $\begin{array}{l}38 . \\
39 .\end{array}$ & $\begin{array}{c}3 \alpha=\beta \\
<<2^{x} \beta>>\end{array}$ & $\begin{array}{l}\text { Elaboration } \\
\text { Enhancement }\end{array}$ & $\begin{array}{l}\text { Skiing down the iron roof ... } \\
\text { When I woke }\end{array}$ \\
\hline & & & \\
\hline
\end{tabular}

\section{Experiential Semantics, Experiential Meaning or Experiential Metafunction}

Experiential Semantics is a resource for representing experience (Halliday, 1994, p. 36) and Experiential Semantics describes a process type 
(processes). According to Halliday (1994), there are 7 processes. Firstly, material process is a process of doing concerned with actions, changes and events, and the material process is represented by verbs such as $d o$, work, walk, sit, eat, drink, drive, ride, and so on. Secondly, mental process is a process of sensing concerned with perception, cognition, emotion and intention, and the mental process is represented by verbs such as see, hear, smell, know, understand, think, love, worry, enjoy, want, hope, intend, and so on. Thirdly, behavioral process is a process of behaving concerned with both physiological and psychological activities, and the behavioral process is represented by verbs such as look at, listen to, ponder, meditate, smile, laugh, sing, dance, and so on. Fourthly, verbal process is a process of saying concerned with statement, question, offer, and command, and the verbal process is represented by verbs such as say, tell, ask, describe, explain, read, teach, complain, and so on. Fifthly, existential process is a process of existing concerned with existence, occurrence and happening, and the existential process is represented by the introductory subject of there (there is, are, was, were, and so on). Sixthly, relational process is a process of being concerned with attribute and identity, and the relational process is represented by some verbs such as be, appear, seem, become, grow, turn, look, sound, play as, act as, mean, imply, comprise, include, represent, stand for, and so on. Finally, causative process is a process of causing concerned with cause and effect, and the causative process is represented by some verbs such as let, make, have, get, and so on.

In fact, the poem is expressed by 25 material clauses, 9 behavioral clauses, 2 relational clauses, 2 causative clauses and 1 mental clause. In addition, the poem is expressed by 24 future clauses, 10 present clauses and 5 past clauses. Therefore, material process and future tense are the automatized patterns because the poem is frequently realized by material and future clauses. Experiential semantics is expressed by transitivity and the analysis of transitivity is presented in Table 3.

\section{Table 3. The Analysis of Transitivity}

\begin{tabular}{cccl}
\hline No. & Process & Tense & Clause \\
\hline 1. & Material & Future & I'll get up soon \\
2. & Material & Future & And I'll leave my bed unmade \\
3. & Material & Future & I'll go outside \\
4. & Material & Future & I'll split off kindling wood \\
\hline
\end{tabular}




\begin{tabular}{|c|c|c|c|}
\hline 5. & Material & Present & That lies beside the gate \\
\hline 6. & Material & Future & And the sun will be high \\
\hline 7. & Material & Present & For I get up late now \\
\hline 8. & Material & Future & I'll drive my axe in the log \\
\hline 9. & Material & Future & And I'll come back with... \\
\hline 10. & Material & Future & And I'll pause \\
\hline 11. & Behavioral & - & To look across Christmas paddocks \\
\hline 12. & Behavioral & - & Aching in the heat \\
\hline 13. & Material & Future & And then I'll go in \\
\hline 14. & Material & Future & [ I'll ] boil water \\
\hline 15. & Material & Future & And [ I'll ] make tea \\
\hline 16. & Material & Future & This afternoon I'll stand out ... \\
\hline 17. & Behavioral & Future & And I'll watch my house \\
\hline 18. & Behavioral & Future & And I'll watch \\
\hline 19. & Material & Present & How the roof reflects the sun \\
\hline 20. & Causative & Present & And the roof make any eyes water \\
\hline 21. & Causative & Present & And the roof makes my eyes close \\
\hline 22. & Material & - & Smeared in the dark of my thoughts \\
\hline 23. & Behavioral & - & To dance \\
\hline 24. & Material & - & And to fade away. \\
\hline 25. & Material & Future & Then the sun will move on \\
\hline 26. & Behavioral & Future & And I'll simply watch \\
\hline 27. & Material & Future & Or I'll work \\
\hline 28. & Behavioral & Future & Or I'll sleep \\
\hline 29. & Material & Future & And evening will draw in \\
\hline 30. & Material & Future & Before the dark, I'll go home \\
\hline 31. & Material & Future & [I'll] light the lamp \\
\hline 32. & Material & Future & [I'll] eat corned beef supper \\
\hline 33. & Material & Future & Setting there at the head ... \\
\hline 34. & Material & Future & And then I'll go to bed \\
\hline 35. & Mental & Past & Last night I thought \\
\hline 36. & Behavioral & Past & [that] I dreamed \\
\hline 37. & Relational & Past & But $<<39>>$ the screaming was a possum \\
\hline 38. & Material & Past & Skiing down the iron roof ... \\
\hline 39. & Behavioral & Past & When I woke \\
\hline
\end{tabular}




\section{Interpersonal Semantics, Interpersonal Meaning or Interpersonal Metafunction}

Interpersonal meaning is a resource for enacting relationship (Halliday, 1994, p. 36) and interpersonal meaning explains a mood type, a modality type and a finiteness type (Butt, Fahey, Spinks \& Yallop, 1995). A mood type comprises declarative, interrogative and imperative. A modality type includes modalization (probability and usuality) and modulation (obligation and inclination). Probability concerns with possibly, probably, and certainly. Usuality deals with sometimes, usually, always, (n)ever, often and seldom. Obligation refers to be allowed to, be permitted to, be supposed to, be expected to, be required to, be forced to, and so on. Inclination points to willingly, anxiously, intentionally, be willing to, be keen to, be determined to, and so on. Meanwhile, a finiteness type corresponds to finite and non-finite clauses.

Actually, the poem is totally encoded by declarative. Moreover, there are 33 finite and 6 non-finite clauses. Accordingly, declarative and finiteness are the automatized patterns because the poem is normally encoded by declarative and finite clauses. Interpersonal semantics is encoded by mood and the analysis of mood is illustrated in Table 4 .

Table 4. The Analysis of Mood

\begin{tabular}{clcl}
\hline No. & Mood & Non-Finiteness & Clause \\
\hline 1. & Declarative & - & I'll get up soon \\
2. & Declarative & - & And I'll leave my bed unmade \\
3. Declarative & - & I'll go outside \\
4. & Declarative & - & I'll split off kindling wood \\
5. Declarative & - & That lies beside the gate \\
6. Declarative & - & And the sun will be high \\
7. Declarative & - & For I get up late now \\
8. Declarative & - & I'll drive my axe in the log \\
9. Declarative & - & And I'll come back with... \\
10. Declarative & - & And I'll pause \\
11. Declarative & Non-Finiteness & To look across Christmas paddocks \\
12. Declarative & Non-Finiteness & Aching in the heat \\
13. Declarative & - & And then I'll go in \\
14. Declarative & - & [I'll ] boil water \\
\hline
\end{tabular}




\begin{tabular}{lcl}
\hline 15. Declarative & - & And ['lll ] make tea \\
16. Declarative & - & This afternoon I'll stand out ... \\
17. Declarative & - & And I'll watch my house \\
18. Declarative & - & And I'll watch \\
19. Declarative & - & How the roof reflects the sun \\
20. Declarative & - & And the roof makes any eyes water \\
21. Declarative & - & And the roof makes my eyes close \\
22. Declarative & Non-Finiteness & Smeared in the dark of my thoughts \\
23. Declarative & Non-Finiteness & To dance \\
24. Declarative & Non-Finiteness & And to fade away \\
25. Declarative & - & Then the sun will move on \\
26. Declarative & - & And I'll simply watch \\
27. Declarative & - & Or I'll work \\
28. Declarative & - & Or I'll sleep \\
29. Declarative & - & And evening will draw in \\
30. Declarative & - & Before the dark, I'll go home \\
31. Declarative & - & [I'll] light the lamp \\
32. Declarative & - & [I'll] eat corned beef supper \\
33. Declarative & - & Setting there at the head ... \\
34. Declarative & - & And then I'll go to bed \\
35. Declarative & - & Last night I thought \\
36. Declarative & - & [that] I dreamed \\
37. Declarative & - & But $<<39>>$ the screaming was a \\
38. Declarative & Non-Finiteness & possum \\
Skiing down the iron roof ... \\
39. Declarative & - & When I woke \\
\hline & &
\end{tabular}

\section{Textual Semantics, Textual Meaning or Textual Metafunction}

Textual meaning is a resource for creating message (Halliday, 1994, p. 36) and textual meaning encodes a Theme type and Theme modes (Eggins, 1994). A Theme type explains unmarked Theme (I went to London last week) and marked Theme (Last week I went to London). The Theme modes include textual Theme (structural conjunction of coordinator and subordinator, cohesive conjunction of moreover, therefore, however, etc., and continuative of well, all right, yes, no, um, and so on.). Interpersonal Theme (comment adjunct of fortunately, honestly, surprisingly, and so on, mood adjunct of generally, actually, especially, practically, and so on, 
vocative of God, darling, John, good morning, and so on and finite of can, may, would, should, and so on), and experiential/topical Theme (participant/noun, process/verb, complement and adjunct).

Actually, the poem is constructed by 36 clauses of unmarked Theme and 3 clauses of marked Theme especially marked Theme takes place in clause 16 (this afternoon), clause 30 (before dark) and clause 35 (last night). Consequently, unmarked Theme is the automatized pattern or the background of the poem, because the poem is normally constructed by clauses of unmarked Theme. Textual semantics is constructed by Theme and the analysis of Theme is offered in Table 5.

Table 5. The Analysis of Theme

\begin{tabular}{|c|c|c|c|c|}
\hline Cause & & Theme & & Rhome \\
\hline Number & Textual & Marked & Unmarked & Rneme \\
\hline 1 & & & I & 'll get up soon \\
\hline 2 & And & & I & 'll leave my bed unmade \\
\hline 3 & & & I & 'll go to outside \\
\hline 4 & & & I & 'll spilt the kindling wood \\
\hline 5 & & & That & lies inside the gate \\
\hline 6 & And & & the sun & will be high \\
\hline 7 & For & & I & 'll drive my axe in the log \\
\hline 8 & & & I & get up late now \\
\hline 9 & And & & I & 'll come back with ... \\
\hline 10 & And & & $\mathrm{I}$ & 'll pause \\
\hline 11 & & & To look & across the Christmas paddocks \\
\hline 12 & & & Aching & in the heat \\
\hline 13 & And & & I & 'll go in \\
\hline 14 & & & I & 'll boil water \\
\hline 15 & And & & I & 'll make tea \\
\hline 16 & & $\begin{array}{c}\text { This } \\
\text { afternoon }\end{array}$ & & I'll stand out in the hill \\
\hline 17 & And & & I & 'll watch my house away below \\
\hline 18 & And & & I & 'll watch \\
\hline 19 & That & & the roof & reflects the sun \\
\hline 20 & & & The roof & makes my eyes water \\
\hline 21 & & & The roof & makes my eyes close \\
\hline
\end{tabular}




\begin{tabular}{|c|c|c|c|c|}
\hline 22 & & & Smeared & in the dark of my thoughts \\
\hline 23 & & & To dance & \\
\hline 24 & And & & to fade & away \\
\hline 25 & Then & & the sun & will move on \\
\hline 26 & And & & I & 'll simply watch \\
\hline 27 & Or & & I & '1l work \\
\hline 28 & Or & & I & ‘ll sleep \\
\hline 29 & And & & evening & will draw in \\
\hline 30 & & $\begin{array}{c}\text { Before the } \\
\text { dark }\end{array}$ & & I'll go home \\
\hline 31 & & & I & '1l light the lamp \\
\hline 32 & & & I & 'll eat my corned beef supper \\
\hline 33 & & & Sitting & there at the head of the lable \\
\hline 34 & $\begin{array}{l}\text { And } \\
\text { then }\end{array}$ & & I & 'll go to bed \\
\hline 35 & & Last night & & I throught \\
\hline 36 & That & & I & dreamed \\
\hline 37 & But & & $\begin{array}{c}\text { the } \\
\text { screaming }\end{array}$ & was a possum \\
\hline 38 & & & Skiing & down \\
\hline 39 & When & & I & woke \\
\hline
\end{tabular}

\section{Logogenetic Process}

According to Halliday and Matthiessen (1998, p. 184-5), logogenesis is a process of making meaning through an instantial system (a changing system) when text unfolds (in the unfolding text). The speaker/writer uses the instantial system (the changing system) as a resource to create a text, whereas the listener/reader uses the instantial system (the changing system) as a resource to interpret the text. Moreover, Matthiessen (1995, p. 40) adds that logogenetic process reveals that lexicogrammatical shift (Cf. Butt, 1988, p. 83 on "latent patterning") coincides with episodic shift (Hasan, 1988, p. 60 on "textual structure"). Textual structure is also called narrative structure (O'Toole, 1983), schematic structure (Martin, 1985), staging structure (Plum, 1988) and generic structure (Eggins, 1994). In this poem, the shifts (changes) are described as follow: 
1. Shift from unmarked Theme (clause 15) to marked Theme (clause 16) coincides with shift from planning to do thing in the morning to planning to do things in the afternoon.

2. Shift from unmarked Theme (clause 29) marked Theme (clause 30) coincides with shift from planning to do things in the afternoon to planning to do things in the evening.

3. Shift from unmarked Theme (clause 34) to marked Theme (clause 35) coincides with shift from planning to do things in the evening to living with no friend

Thus, the instantial system of process is used as a resource for making meanings in the poem, and logogenetic process is demonstrated in Table 6.

Table 6. Logogenetic Process

\begin{tabular}{cll}
\hline $\begin{array}{c}\text { Clause } \\
\text { Number }\end{array}$ & $\begin{array}{c}\text { Lexicogrammatical shift } \\
\text { Cf. latent patterning }\end{array}$ & $\begin{array}{l}\text { Episodic shift } \\
\text { Cf. textual structure }\end{array}$ \\
\hline 1 & unmarked Theme & Planning to do things \\
15 & unmarked Theme & in the morning \\
16 & marked Theme & Planning to do things \\
29 & unmarked Theme & in the afternoon \\
30 & marked Theme & Planning to do things \\
34 & unmarked Theme & in the evening \\
35 & marked Theme & Living with no friend \\
39 & unmarked Theme & but a possum \\
\hline
\end{tabular}

\section{Lexical Cohesion}

Lexical cohesion consists of several lexical chains and each chain has a number of lexical items. The poem is realized by 11 lexical chains consisting of 108 lexical items. The lexical cohesion indicates that the three main lexical chains are persona (chain 1), material process (chain 2) and cohyponym (chain 9). Thus, the main lexical chains are the automatized patterns because the poem is frequently realized by the main lexical chains. Then, lexical cohesion is displayed in Table 7. 
Table 7. Lexical Cohesion

\begin{tabular}{|c|c|c|c|}
\hline No. & Lexical Chain & Lexical Item & Total \\
\hline 1. & Persona & $\mathrm{I}(24 \mathrm{x})$ & 24 \\
\hline 2. & Material Process & $\begin{array}{l}\text { Get up, leave, go, split, lies, get up, drive, } \\
\text { come, pause, go, boil, stand, reflect, } \\
\text { smeared, fade, move, work, draw, } \\
\text { coming, go, light, eat, sitting, go, skiing }\end{array}$ & 25 \\
\hline 3. & Behavioral Process & $\begin{array}{l}\text { Look, aching, watch, watch, dance, sleep, } \\
\text { dreamed, woke }\end{array}$ & 8 \\
\hline 4. & Causative Process & Makes, makes & 2 \\
\hline 5. & Mental Process & Thought & 1 \\
\hline 6. & Repetition & $\begin{array}{l}\text { Log- log, roof-roof, sun-sun, water- } \\
\text { water, bed-bed }\end{array}$ & 10 \\
\hline 7. & Synonym & $\begin{array}{l}\text { Trees }=\text { nettles, water }=\text { tea, axe }=\text { iron, } \\
\text { sun }=\text { heat, } \\
\text { paddocks }=\text { yard, house }=\text { home }\end{array}$ & 12 \\
\hline 8. & Antonym & Bright $><$ dark & 2 \\
\hline 9. & Cohyponym & $\begin{array}{l}\text { Eyes-hand, visions-thoughts, gate-roof, } \\
\text { bed-table, } \\
\text { time: soon-late-now, afternoon-evening- } \\
\text { last night }\end{array}$ & 14 \\
\hline 10. & Meronym & Possum-claws & 2 \\
\hline & Collocation & $\begin{array}{l}\text { Boil-water, light-lamp, eat-supper, } \\
\text { sitting-table }\end{array}$ & 8 \\
\hline & & Overall total & 108 \\
\hline
\end{tabular}

\section{Subject Matter}

Field includes subject matter as a special manifestation (Halliday, 1993, p. 10), and Field is realized by experiential meaning (Halliday, 1993, p. 143). Then, Field is encoded by both experiential meaning and lexical cohesion (Eggins, 1994, p.112). In addition, subject matter is expressed by lexical chains (Butt, 1988, p. 177), and specifically subject matter is indicated by the main lexical chains (Butt, 1988, p. 182). Thus, subject matter is expressed by both experiential meaning and lexical cohesion. Experiential Semantics shows that experiential meaning is frequently realized by material process. Lexical Cohesion also indicates that the poem is frequently expressed by material process. It means that subject matter is frequently encoded by material process. In fact, material process reveals 
that the functional constituents are Actor (I), Material Process (plan to do), Goal (daily routine) and Circumstance (from morning to evening). In conclusion, the subject matter is that the widower plans to do his daily works from morning till evening. The analysis of material process is mapped out in Table 8 .

Table 8. The Analysis of Material Process

\begin{tabular}{|c|c|c|c|c|}
\hline No. & Actor & Material Process & Goal & Circumstance \\
\hline 1. & I & 'll get up & \multirow{3}{*}{ my bed } & soon \\
\hline 2. & I & 'll leave & & unmade (untidily) \\
\hline 3. & I & ‘ll go & & outside \\
\hline 4. & I & '1l spilt out & $\begin{array}{l}\text { kindling } \\
\text { wood }\end{array}$ & \\
\hline 5. & I & Get up & \multirow{3}{*}{ my axe } & late now \\
\hline 6. & I & 'll drive & & in the $\log$ \\
\hline 7. & I & 'll come back & & in with... \\
\hline 8. & I & 'll go in & \multirow{4}{*}{$\begin{array}{c}\text { water } \\
\text { tea }\end{array}$} & \\
\hline 9. & I & 'll boil & & \\
\hline 10. & I & 'll make & & \\
\hline 11. & I & 'll stand out & & this afternoon on the hill \\
\hline 12. & I & 'll work & \multirow{6}{*}{$\begin{array}{l}\text { the lamp } \\
\text { my corned } \\
\text { beef }\end{array}$} & \\
\hline 13. & I & 'll go & & home before the dark \\
\hline 14. & I & '1l light & & \\
\hline 15. & I & 'll eat & & \\
\hline 16. & I & sitting & & at the head of the table \\
\hline 17. & I & 'll go & & to bed \\
\hline
\end{tabular}

\section{SEMIOTIC SYSTEM OF VERBAL ART}

A semiotic system of verbal art consists of verbalization (the deep level of meaning), symbolic articulation (the deeper level of meaning) and theme (the deepest level of meaning).

\section{Verbalization: The Deep Level of Meaning}

Logical Semantics shows that extension is automatized, so a combination of extension, enhancement and projection is foregrounded. Thus, the foregrounding of logical relation takes place in clauses $35,36,37$, 
38 and 39. Experiential Semantics indicates that material process is automatized, so other processes are foregrounded. Therefore, the foregrounding of process happens to clauses $6,11,12,17,18,19,20,21$, $22,23,26,28,35,36,37$, and 39. Experiential Semantics also explains that future tense is automatized, so other tenses are foregrounded. Accordingly, the foregrounding of tense exists in clauses $5,7,19,20,21,35,36,37$ and 39. Interpersonal Semantics describes that finiteness is automatized, so non-finiteness is foregrounded. Consequently, the foregrounding of nonfiniteness occurs in clauses 11, 12, 22, 23, 24, and 38. Textual Semantics illustrates that unmarked Theme is automatized, so marked Theme is foregrounded. As a result, the foregrounding of Theme exists in clauses 16, 30 and 35.

Patterning of all foregrounded patterns points toward clauses 35,36 , 37, 38 and 39. It means that consistency of foregrounding converges toward the last clause complex due to the foregrounding of logical relation, process, tense, non-finiteness and tense. Then, the consistency of foregrounding makes the foregrounded patterns of the last clause complex produce consistently foregrounded meaning which is also called the deep level of meaning and the first order meaning. In short, the consistently foregrounded meaning is called the deep level of meaning: last night I thought that I dreamed but the screaming was a possum skiing down the iron roof on little moonlit claws when I woke.

\section{Symbolic Articulations: The Deeper Level of Meaning}

The deep level of meaning functions as sign, symbol or metaphor of the deeper level of meaning which is also called the second under meaning and literary meaning. Verbalization shows that the deep level of meaning describes an ambiguity between the dream of screaming and the desolation or loneliness because of the death of his spouse. Logogenetic Process indicates that the textual structure tells about living with no friend. In brief, the deeper level of meaning is about the complete severance from human companionship.

\section{Theme: The Deepest Level of Meaning}

The deeper level of meaning creates the deepest level of meaning which is also called Theme and the third order meaning. Hasan (1985, p. 97) states that Theme is the deepest level of meaning in verbal art; it is what a text is about when dissociated from the particularities of that text. In 
its nature, the Theme of verbal art is very close to generalizations which can be viewed as a hypothesis about some aspect of the social life of man. Moreover, Hasan $(1985$, p. 54) adds that the deepest level of meaning is a meaning that arises from saying one thing and meaning another. In this poem, saying one thing (the complete isolation from human companionship) means another (interpersonal relationship). In summary, the deepest level of meaning is about personal relationship.

\section{CONCLUSION}

The lexicogrammatical analysis produces semantic components and there are two kinds of semantic patterns such as automatized and foregrounded. On the one hand, the automatized pattern produces the automatized meaning, and in turn the automatized meaning produces subject matter. At the stratum of Verbalization, on the other hand, consistency of foregrounding makes some foregrounded patterns produce consistently foregrounded meaning which is also called the deep level of meaning and the first order meaning. At the stratum of symbolic articulation, the deep level of meaning functions as symbol, sign or metaphor of the deeper level of meaning which is also called the second order meaning and literary meaning. At the stratum of Theme, the deeper level of meaning creates the deepest level of meaning which is also called Theme and the third order meaning. In summary, there is a symbolic relation between lexicogrammar and Theme in verbal art. Then the meanings in the poem are outlined in Table 9

Table 9. Meanings of Verbal Art Semiotics

\begin{tabular}{lll}
\hline Verbalization & Symbolic Articulation & Theme \\
\hline $\begin{array}{l}\text { Consistenly } \\
\text { Foregrounded Meaning }\end{array}$ & Literary Meaning & Theme \\
$\begin{array}{l}\text { The Deep Level } \\
\text { of Meaning }\end{array}$ & $\begin{array}{l}\text { The Deeper Level } \\
\text { of Meaning }\end{array}$ & $\begin{array}{l}\text { The Deepest Level } \\
\text { of Meaning }\end{array}$ \\
The First & The Second & The Third \\
\hline
\end{tabular}

\section{REFERENCES}

Butt, D. (1988). Randomness, order and the latent patterning of text. In D. Birch, \& M. O' Toole (Eds.), Functions of style (pp. 30-44). London: Pinter Publishers. 
Butt, D., Fahey, R., Spinks, S., \& Yallop, C. (1995). Using functional grammar. Sydney: Macquarie University.

Eggins, S. (1994). An introduction to systemic functional linguistics. London: Pinter Publishers.

Halliday, M. A. K., \& Hasan, R. (1985). Language, context, and text: Aspects of language in a social-semiotic perspective. Melbourne: Deakin University Press.

Halliday, M. A. K. (1993). Language as a social semiotic. London: Edward Arnold.

Halliday, M. A. K., \& Matthiessen, C.. (1999). Construing experience through meaning: A language-based approach to cognition. Berlin: de Gruyter.

Hasan, R. (1985). Linguistics, language and verbal art. Melbourne: Deakin University Press.

Hasan, R. (1988). The analysis of one poem: Theoretical issues in practice. In D. Birch, \& M. O' Toole (Eds.), Functions of Style (pp. 52-64). London: Pinter Publishers.

Hasan, R. (1996). On teaching literature across cultural distances. In J. E. James (Ed.), The language-culture connection (pp. 45-60). [Anthology series 37]. Singapore: Seameo Regional Language Center

Martin, J. R. (1985). Process and text: Two aspects of semiosis. In J. D. Benson, \& W. S. Graves (Eds.), Systemic perspectives on discourse (pp. 17-34). Norwood, New Jersey: Ablex.

Martin, J. R. (1992). English text system and structure. Amsterdam: John Benjamins Publishing.

Mukarovsky, J. (1977). The word and verbal art. (J. Burbank, \& P. Steiner, Trans.). New Haven: Yale University Press.

Matthiessen, C. (1995). Lexicogrammatical cartography: English systems. Tokyo, Taipei, Dallas: International Language Sciences Publishers.

Preminger, A. (1974). Princeton encyclopaedia of poetry and poetics. Princeton: Princeton University Press.

Plum, G. A. (1988). Text and contextual conditioning in spoken English: A genre based approach. Unpublished doctoral dissertation, University of Sydney, Sydney. 